\title{
Changes of a refractive index of tellurite glass
}

\author{
M. Reben, ${ }^{* 1}$ J. Wasylak, ${ }^{1}$ and J. Jaglarz ${ }^{2}$ \\ ${ }^{1}$ Faculty of Materials Science and Ceramics, AGH-University of Science and Technology, \\ Mickiewicza 30, 30-059 Cracow, \\ ${ }^{2}$ Institute of Phisics, Cracow University of Technology, Podchorą̇ych 1, 30-084 Cracow
}

Received March 4, 2010; accepted March 23, 2010; published March 31, 2010

\begin{abstract}
The goal of this work was to investigate the influence of rare earth ions such as $\mathrm{Tm}^{3+}, \mathrm{Yb}^{3+}$ on physico-chemical properies of tellurite glass from the $\mathrm{TeO}_{2}-\mathrm{WO}_{3}-\mathrm{PbO}-\mathrm{PbF}_{2}-\mathrm{Na}_{2} \mathrm{O}$ system. The thermal characteristics of tellurite glass $\mathrm{Tm}^{3+}, \mathrm{Yb}^{3+}$ doped have been presented The effect of the glass crystallization on thermal stability of the glass and crystallizing phases formed upon heat treatment were investigated by DTA/DSC/, XRD methods. The influence of ions of rare earth elements, i.e. $\mathrm{Tm}^{3+}$ and $\mathrm{Yb}^{3+}$, onto changes of refractive index of tellurite glass were examined.
\end{abstract}

Among numerous oxide glasses, tellurite glasses of the system $\mathrm{TeO}_{2}-\mathrm{WO}_{3}-\mathrm{PbO}$, have unique optical and magneto-optical properties, resulting from big mass and polarizability of $\mathrm{Pb}^{2+}$ ions. They are characterized by a high refractive index of about 2.0, as well as an absorption edge located at $6 \mu \mathrm{m}[1]-[3]$. High value of the refractive index of tellurite glasses allows using such materials in optical waveguides, where a self-focusing effect is observed $[4,5]$. They are used in infrared optics, optical-electronics, magneto-optics, as well as in optical waveguide technology [6,7].

The following raw materials were used to prepare the batches: $\mathrm{TeO}_{2}, \mathrm{WO}_{3}, \mathrm{PbO}, \mathrm{Na}_{2} \mathrm{O}, \mathrm{PbF}_{2}, \mathrm{Tm}_{2} \mathrm{O}_{3}, \mathrm{Yb}_{2} \mathrm{O}_{3}$. The batches were based on the $\mathrm{TeO}_{2}-\mathrm{WO}_{3}-\mathrm{PbO}-\mathrm{PbF}_{2}-$ $\mathrm{Na}_{2} \mathrm{O}$ tellurite glass system, with rare earths admixtures: $\mathrm{Tm}^{3+}, \mathrm{Yb}^{3+}$. For each batch, high purity initial materials were fully mixed and melted in covered gold crucibles in an electric furnace at a temperature of $850^{\circ} \mathrm{C}$, in air atmosphere. The compositions of glasses are listed in Table 1.

Table.1. Chemical composition of glass

\begin{tabular}{|c|c|c|c|c|c|c|c|}
\hline \hline \multirow{2}{*}{$\begin{array}{c}\text { Glass } \\
\text { No. }\end{array}$} & \multicolumn{7}{|c|}{ Chemical composition in \% mole } \\
\cline { 2 - 8 } & $\mathrm{TeO}_{2}$ & $\mathrm{WO}_{3}$ & $\mathrm{PbO}$ & $\mathrm{Na}_{2} \mathrm{O}$ & $\mathrm{PbF}_{2}$ & $\mathrm{Tm}_{2} \mathrm{O}_{3}$ & $\mathrm{Yb}_{2} \mathrm{O}_{3}$ \\
\hline P1 & 60 & 28 & 2 & 2 & 8 & - & - \\
\hline P2 & 60 & 28 & 7 & 2 & 3 & 0,08 & - \\
\hline P3 & 60 & 28 & 7 & 2 & 3 & - & 0,08 \\
\hline
\end{tabular}

The crystallization ability of obtained glasses was determined on the basis of DTA/DSC measurements,

\footnotetext{
*E-mail: manuelar@agh.edu.pl
}

conducted on a Perkin-Elmer DTA-7 system, operating in the heat flux DSC mode. The spectroscopic measurements of $\Psi$ and $\Delta$ of the presented glasses were made using a Woollam M2000 spectroscopic ellipsometer, in a spectral range of 190-1700 $\mathrm{nm}$. The samples were measured for three angles of incidence $\left(55^{\circ}, 60^{\circ}, 65^{\circ}\right)$. Ellipsometric parameters (angles $\Delta$ and $\psi$ ) were determined with accuracy of about $0,01^{\circ}$, according to the basal ellipsometric relation:

$$
\rho=\left|\frac{r_{p}}{r_{s}}\right| e^{i \Delta}=\operatorname{tg}(\Psi) e^{i \Delta}
$$

During the heat treatment, tellurite glasses from the $\mathrm{TeO}_{2}-\mathrm{WO}_{3}-\mathrm{PbO}-\mathrm{PbF}_{2}-\mathrm{Na}_{2} \mathrm{O}$ system with admixtures of rare earths $\mathrm{Tm}{ }^{3+}, \mathrm{Yb}^{3+}$, beside thermal effects characteristic for standard modification of the glassy state, expose an additional exothermal effect located near transformation temperature $T_{\mathrm{g}}$. This effect is related with fluoride phase crystallization of the type: lead fluoride with included ions of RE elements $\left(\mathrm{Yb}^{3+}, \mathrm{Tm}^{3+}\right)$ (Fig. 1).

The presence of the crystalline phase within the range of the effect occurrence was proved with X-ray phase analysis XRD (Tab.2.). Based on the analysis of the DTA/DSC curves of glasses P1, P2, P3, it was proved that the presence of a clearly visible exothermal effect within the temperature range $500^{\circ} \mathrm{C}-600^{\circ} \mathrm{C}$ is directly related with the $\mathrm{PbF}_{2}$ nanocrystallization process. In the examined group of glasses P1, P2, P3, differing in their admixture type in the form of rare earths, the influence of the RE type onto glassy state transformation, as well as onto crystallization process, was observed. For glasses P2, P3 with $\mathrm{Tm}^{3+}, \mathrm{Yb}^{3+}$ ion admixtures, the transformation temperature is displaced toward higher temperatures, as compared with the reference glass (1) without any admixture (Table.2). Simultaneously, the glassy

state 


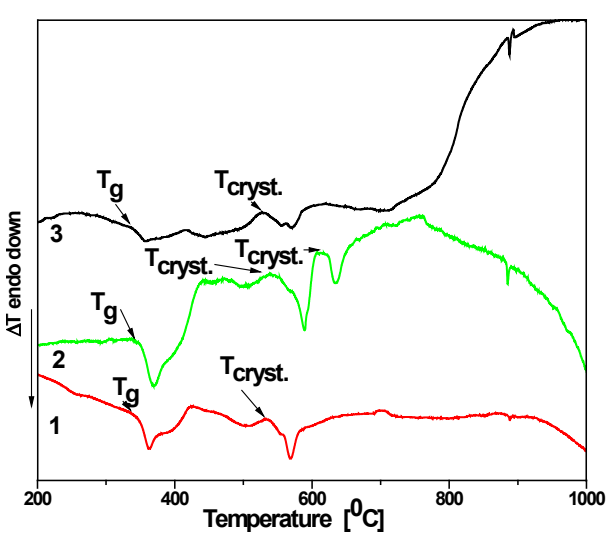

Fig.1. DTA/DSC curves of tellurite glasses.

transformation temperature rise is accompanied by smaller changes of mole heat $\Delta \mathrm{C}_{\mathrm{p}}$, which can indicate a strength increase, as well as elasticity improvement of the glasses in question. Under the influence of the admixture, also the temperature of a maximal crystallization effect is displaced toward higher temperatures. The values of heat parameters - drop of thermal stability $\Delta \mathrm{T}$ in glasses $\mathrm{P} 1$, $\mathrm{P} 2$ are indicative of better ceramization of glasses - up to fluoride phase crystallization in the form of $\mathrm{PbF}_{2}$ nanocrystallites (Table.2).

Table 2. Characteristic temperatures of tellurite glasses

\begin{tabular}{|c|c|c|c|c|c|c||}
\hline $\begin{array}{c}\text { Sample } \\
\text { No }\end{array}$ & $\begin{array}{c}\mathrm{T}_{\mathrm{g}} \\
{\left[{ }^{\circ} \mathrm{C}\right]}\end{array}$ & $\begin{array}{c}\Delta \mathrm{C}_{\mathrm{p}} \\
{\left[\mathrm{J} \cdot \mathrm{g}^{-1} \cdot{ }^{\circ} \mathrm{C}^{-}\right.} \\
\left.{ }^{1}\right]\end{array}$ & $\begin{array}{c}\mathrm{T}_{\max } \\
\text { cryst. } \\
{\left[{ }^{\circ} \mathrm{C}\right]}\end{array}$ & $\begin{array}{c}\Delta \mathrm{H} \\
{\left[\mathrm{J} \cdot \mathrm{g}^{-1}\right]}\end{array}$ & $\begin{array}{c}\Delta \mathrm{T}= \\
\mathrm{T}_{\text {cryst. }}-\mathrm{T}_{\mathrm{g}} \\
{\left[{ }^{\circ} \mathrm{C}\right]}\end{array}$ & $\begin{array}{c}\text { Type of } \\
\text { crystallization } \\
\text { phase }\end{array}$ \\
\hline P1 & 340 & 0,197 & 528 & 21,56 & 188 & $\mathrm{TeO}_{2}$ \\
\hline P2 & 358 & 0,296 & 553 & 20,78 & 195 & $\mathrm{TeO}_{2}$ \\
& & & 620 & 20,34 & 262 & $\mathrm{PbF}_{2}$ \\
\hline P3 & 347 & 0,196 & 527 & 23,54 & 180 & $\mathrm{PbF}_{2}$ \\
\hline
\end{tabular}

The spectral dependence of ellipsometric angles of the P1, P2 and P3 glass samples has been shown in Fig. 2.Additionally, generated values of $\Psi \square$ and $\Delta$ obtained from the Cauchy model have been presented in Fig. 2.

The Cauchy model describes dispersion relations for $n$ and $k$ indices, namely:

$$
\begin{gathered}
n(\lambda)=A+\frac{B}{\lambda^{2}}+\frac{C}{\lambda^{4}} \\
k(\lambda)=K e^{\beta\left(\frac{h c}{\lambda}-E_{\text {bandedge }}\right)}
\end{gathered}
$$

where $\mathrm{A}, \mathrm{B}, \mathrm{C}$ and and $\beta$ are constants. $\mathrm{K}$ and $\mathrm{E}_{\mathrm{Bandegde}}$ are the fit parameters describing the Urbach absorption tail and allow us to define the dispersion shape of an extinction coefficient [8]. The values of these fit parameters, for P1, P2 and P3 glass samples, have been presented in Table 3.

Table 3. Values of fitted parameters

\begin{tabular}{|l|l|l|l|l|l|}
\hline $\begin{array}{l}\text { Glass } \\
\text { No }\end{array}$ & $\begin{array}{l}\text { A (n dla } \\
633 \mathrm{~nm})\end{array}$ & $\mathrm{B} 10^{-2}$ & $\mathrm{C} \times 10^{-4}$ & $\begin{array}{l}\mathrm{K} \times 10^{-} \\
4\end{array}$ & $\mathrm{r}[\mathrm{nm}]$ \\
\hline P1 & 1.871 & 1.946 & 2.641 & $0.50 \pm$ & $9.27 \pm$ \\
& \pm 0.119 & \pm 0.028 & \pm 0.033 & 0.020 & 1.250 \\
\hline P2 & 1.824 & 1.244 & $2.630 \pm$ & $0.164 \pm$ & $13.41 \pm$ \\
& \pm 0.135 & \pm 0.025 & 0.036 & 0.092 & 1.90 \\
\hline P3 & 1.989 & 1.511 & $0.348 \pm$ & $0.117 \pm$ & $16.39 \pm$ \\
& \pm 0.070 & \pm 0.023 & 0.307 & 0.019 & 1.02 \\
& & & & & \\
\hline
\end{tabular}

Figure 3 illustrates $\mathrm{n}$ and $\mathrm{k}$ dispersive relations within 190 to $1700 \mathrm{~nm}$ spectral range, determined for the studied samples.

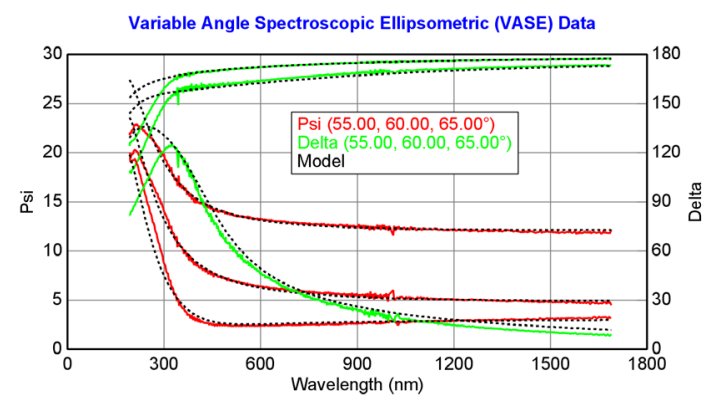

2a)

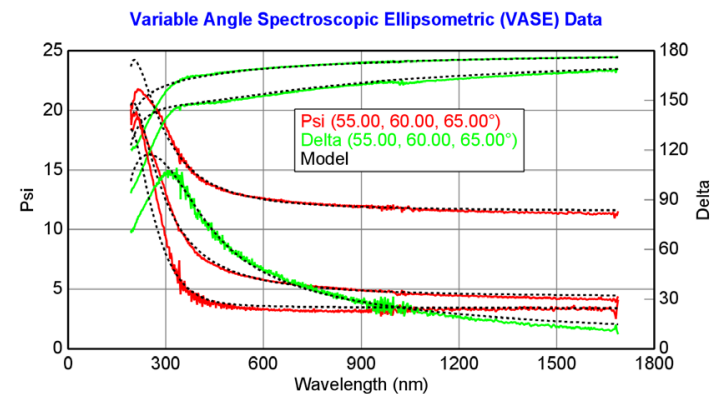

2b)

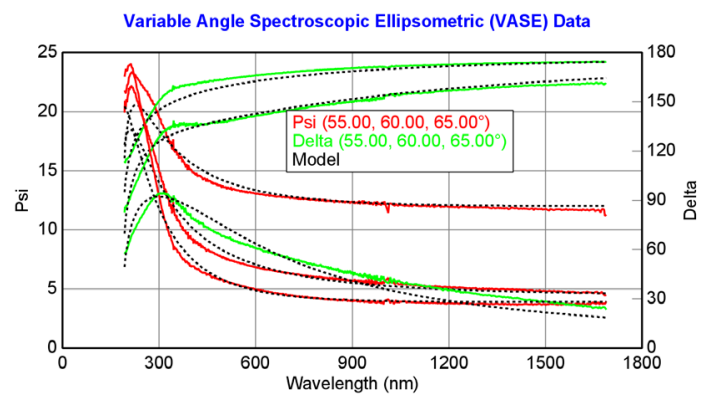

2c)

Fig. 2. Spectral dependence of ellipsometric angles $\Psi$ and $\Delta$ measured for $\mathrm{P} 1, \mathrm{P} 2$, and $\mathrm{P} 3$ glass samples, respectively 
Coefficients $n$ and $k$ of tellurite glasses P1, P2, P3 expressed in the wavelength function and determined on the basis of ellipsometric measurements within 190 do $1700 \mathrm{~nm}$ spectrum range are shown in Fig. 3.

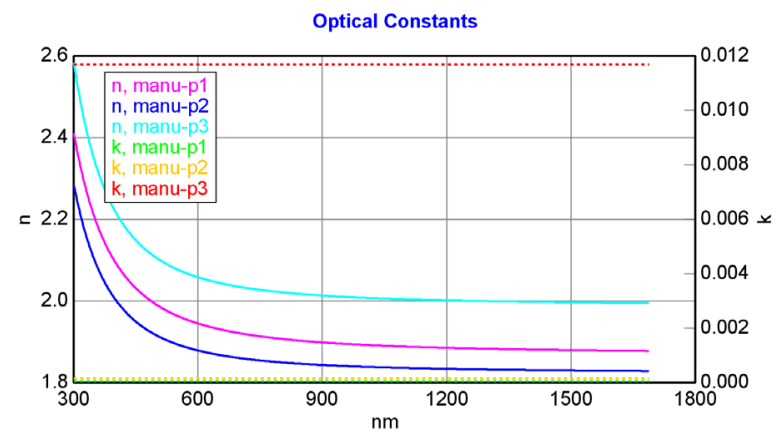

Fig. 3. Cauchy dispersion dependences of glasses P1, P2, P3 determined for $n-$ and $k$.

The appearance of surface roughness, which can be described using the Bruggeman effective medium approximation (EMA), was assumed for the investigated samples [9]. This approximation uses 50:50 mixture of the material and air, at the sample surface getting optical constants that approximate the effect of surface roughness. The obtained values of $\sigma$, are presented in column 6 of Table 3 .

Based on the conducted thermal examinations, it has been proved that crystallization ability of tellurite glasses of the system $\mathrm{TeO}_{2}-\mathrm{WO}_{3}-\mathrm{PbO}-\mathrm{PbF}_{2}-\mathrm{Na}_{2} \mathrm{O}$ with admixtures of rare earths elements strongly depends on the RE type. It has been proved that the admixture of ions $\mathrm{Yb}^{3+}$ and $\mathrm{Tm}^{3+}$ results in the appearance of an exothermal effect related with $\mathrm{PbF}_{2}$ crystallization on DTA/DCS curves. It has been observed in the case of glass P2, with admixtures of ions $\mathrm{Tm}^{3+}$, that the crystallization process is run in two phases; within the temperature range 400$600^{\circ} \mathrm{C}$. Thellurium oxide $\mathrm{TeO}_{2}$ is a crystallization phase at a temperature of $553^{\circ} \mathrm{C}$, whereas the heat treatment of this glass at $620^{\circ} \mathrm{C}$ causes the appearance of another lowphonon energy crystallization phase of the $\mathrm{PbF}_{2}$ type. Based on thermal examinations of the glasses in question, it has been proved that rare earths elements which are present in the structure cause the displacement of a glassy state transformation temperature towards higher levels, and lowered values of parameters of thermal stability $\Delta \mathrm{T}=\mathrm{T}_{\text {cryst. }}-\mathrm{T}_{\mathrm{g}}$ indicate an improvement in a glass tendency for fluoride phase crystallization.
Refraction indexes of tellurite glasses reach very high values of over 1,85 within all measured spectral range, and they are considerably higher than in the case of standard optical glasses. Ellipsometric examinations have proved that ions of rare earth elements, i.e. $\mathrm{Tm}^{3+}$ and $\mathrm{Yb}^{3+}$, have a considerable influence on the changes of an refractive index of basal glass P1 (without RE admixture). Doping $\mathrm{Tm}^{3+}$ ions to a tellurium matrix of glass from the system $\mathrm{TeO}_{2}-\mathrm{WO}_{3}-\mathrm{PbO}-\mathrm{PbF}_{2}-\mathrm{Na}_{2} \mathrm{O}$ results in the reduction of a refractive index by about 0.03 (glass $\mathrm{P} 2$ ). However, doping with $\mathrm{Yb}^{3+}$ ions (glass $\mathrm{P} 3$ ) results in its considerable rise by about 0,12 within the visible range) with respect to base glass $\mathrm{P} 1$. Doped tellurite glass has also bigger roughness, whereas the highest influence on roughness rise was observed in the case of glass doped with $\mathrm{Yb}^{3+}$ ions.

It can be concluded that admixtures of $\mathrm{Yb}^{3+}$ ions have the most considerable influence on the rise in tellurite glasses refractive index r. Additional optical and thermal examinations will be conducted in order to determine the optimal contents of ytterbium ions, which change $n$ values in the most effective manner.

\section{References}

[1] L. M. Fortes, L. F. Santos, M. C. Gonçalves, R. M. Almeida, J. NonCryst. Solids 324, 150-158 (2003).

[2] J. Wasylak, M.Reben, European Glass Technology-European Journal of Glass Science and Technology: Physics and Chemistry of Glasses, 48, 264-250 (2007).

[3] T. Kosuge, Y. Benino, V. Dimitrov, R. Sato, T. Komatsu, J. NonCFigt. Solids 242, 154-164 (1998)

[4] D.W. Hall, M.A. Newhouse, N.F. Borrelli, W.H. Dumbaugh, D.L. Weidman,", J. Non-Cryst. Solids 103, 179-194 (1988).

[5] E.M. Vogel, M.J. Weber, D.M. Krol, Phys.Chem. Glasses 32, 231-253 (1991).

[6] M. Reben, J. Wasylak, D. Dorosz, Proceedings of SPIE 7120, (2008).

[7] M. Reben, J. Wasylak, P. Wantuch, Polska Konferencja Optyczna PKO 2009.

[8] F. Urbach, "The long wavenlength of photographic sensitivity and of thr electronic absorption of solids", Phys. Rev. 92, 1324 (1953).

[9] D.A.G.Bruggeman, „Berechnung verschiedener physikalischer konstanten von heterogenen substanzen“, Ann. Phys. (Leipzig) B 24, 636-674. 